See Article page 196.

\section{Commentary: Combine the right size with the right shape}

\author{
Manan Desai, $\mathrm{MD},{ }^{\mathrm{a}}$ and Can Yerebakan, $\mathrm{MD}^{\mathrm{b}}$
}

Early outcomes of tetralogy of Fallot repair are excellent. Long-term survival after repair reaches $95 \%$ after 25 years. $^{1}$ However, many patients continue to have long-term sequelae in the form of pulmonary regurgitation or, to a lesser extent, residual right ventricular outflow tract (RVOT) obstruction. Depending on clinical and hemodynamic implications, these residual lesions might require intervention using pulmonary valve implantation and/or relief of a residual obstruction. As the cohort of patients with repaired tetralogy of Fallot (rTOF) grows, more data will be available to reflect on factors that can indicate how we may minimize late complications and reinterventions.

Cardiac magnetic resonance (CMR) imaging is an important tool in monitoring of patients with tetralogy of Fallot following surgical repair. ${ }^{2}$ It has the advantage of being a noninvasive, radiation-free modality largely unaffected by postoperative limited windows. CMR provides an accurate assessment of cardiac volumes, function, and anatomy. Several studies using CMR in the past decade have helped us define variables like right ventricular (RV) enddiastolic and end-systolic volumes and function that indicate the need for intervention while reverse remodeling is still possible. ${ }^{3,4}$ Recently, we have been able to guide, based on CMR volumes and flow measurements, which patients are likely to benefit from a pulmonary valve replacement while asymptomatic. ${ }^{5}$

In this issue of the Journal, Shen and colleagues ${ }^{6}$ have added to existing data that enable us to better interpret

From the a Department of Cardiothoracic Surgery, Lucile Packard Children's Hospital, Stanford University, Palo Alto, Calif and ${ }^{\mathrm{b}}$ Department of Cardiovascular Surgery, Children's National Heart Institute, Children's National Health System, The George Washington University School of Medicine and Health Sciences, Washington, DC.

Disclosures: The authors reported no conflicts of interest.

The Journal policy requires editors and reviewers to disclose conflicts of interest and to decline handling or reviewing manuscripts for which they may have a conflict of interest. The editors and reviewers of this article have no conflicts of interest.

Received for publication Nov 17, 2020; revisions received Nov 17, 2020; accepted for publication Nov 18, 2020; available ahead of print Nov 30, 2020.

Address for reprints: Manan Desai, MD, Department of Cardiothoracic Surgery, Lucile Packard Children's Hospital, Stanford University, Falk Building, 870 Quarry Rd, Palo Alto, CA 94304 (E-mail: mdesai2@stanford.edu).

J Thorac Cardiovasc Surg 2021;162:206-7

$0022-5223 / \$ 36.00$

Copyright (c) 2020 by The American Association for Thoracic Surgery

http://dx.doi.org/10.1016/j.jtcvs.2020.11.080

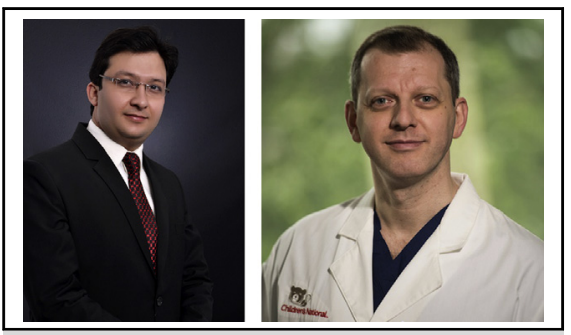

Manan Desai, MD, and Can Yerebakan, MD

CENTRAL MESSAGE

The shape of the right ventricular

outflow tract in repaired tetral-

ogy of Fallot may be an impor-

tant factor to influencing the

outcome.

CMR of rTOF. They have shifted the focus from solely cardiac volumes, which heretofore have been studied extensively, onto shapes of the RVOT. They divide the RVOT shapes to into 2 broad categories: tubular and nontubular. They further classify the nontubular shapes into (1) pyramid with the narrow end toward bifurcation, (2) hourglass, and (3) reverse-trapezoid with the narrow end toward the infundibulum. The pyramid shape (which would be expected with a wide transannular patch) had the greatest RV volume and longest QRS duration, whereas the inverse-trapezoid shape (as would be expected with a valve-sparing repair) had the smallest RV volume and shortest QRS duration. Although the shape did not affect exercise tolerance, branch pulmonary artery stenosis was an important predictor of diminished exercise capacity. It would have been worthwhile to explore an association between various surgical strategies (eg, transannular or transinfundibular valve-sparing) and the various shapes defined in their analyses. This information could potentially influence and/or justify choice of a particular surgical approach.

Finding an evidence-based answer continues to be a challenge in the field of medicine. ${ }^{7}$ Recently, a propensity score-adjusted study of large registry of rTOF (INDICATOR) by Bokma and colleagues has called into question the dogma that pulmonary valve replacement alters the unnatural history of rTOF patients and has shown that proactive early intervention might even be detrimental. ${ }^{8}$ The small number of adverse events, even in large cohorts, and a shorter duration of follow-up contribute to the conflicting results of different studies. Thus, in the field of 
CMR, newer imaging adjuncts, such as feature-tracking to measure ventricular strain, have been added to the armamentarium for predicting optimal timing of pulmonary valve replacement. ${ }^{9}$ We congratulate the authors for their contribution to this expanding field of imaging in patients of rTOF.

\section{References}

1. Smith CA, McCracken C, Thomas AS, Spector LG, St Louis JD, Oster ME, et al. Long-term outcomes of tetralogy of Fallot: a study from the pediatric cardiac care consortium. JAMA Cardiol. 2019;4:34-41.

2. Geva T. Repaired tetralogy of Fallot: the roles of cardiovascular magnetic resonance in evaluating pathophysiology and for pulmonary valve replacement decision support. J Cardiovasc Magn Reson. 2011;13:9

3. Heng EL, Gatzoulis MA, Uebing A, Sethia B, Uemura H, Smith GC, et al. Immediate and midterm cardiac remodeling after surgical pulmonary valve replacement in adults with repaired tetralogy of Fallot: a prospective cardiovascular magnetic resonance and clinical study. Circulation. 2017;136:1703-13.
4. Oosterhof T, van Straten A, Vliegen HW, Meijboom FJ, van Dijk AP, Spijkerboer AM, et al. Preoperative thresholds for pulmonary valve replacement in patients with corrected tetralogy of Fallot using cardiovascular magnetic resonance. Circulation. 2007;116:545-51.

5. He F, Feng Z, Chen Q, Jiao Y, Hua Z, Zhang H, et al. Whether pulmonary valve replacement in asymptomatic patients with moderate or severe regurgitation after tetralogy of Fallot repair is appropriate: a case-control study. J Am Heart Assoc. 2019;8:e010689.

6. Shen W-C, Chen C-A, Chang C-I, Chen Y-S, Huang S-C, Wu M-H, et al Outflow tract geometries are associated with adverse outcome indicators in repaired tetralogy of Fallot. J Thorac Cardiovasc Surg. 2021;162: 196-205.

7. Vonder Muhll IF. Timing and results of pulmonary valve replacement for pulmonary regurgitation in repaired tetralogy of Fallot: a challenge for evidence-based medicine. Can J Cardiol. 2019;35:1620-2.

8. Bokma JP, Geva T, Sleeper LA, Babu Narayan SV, Wald R, Hickey K, et al. A propensity score-adjusted analysis of clinical outcomes after pulmonary valve replacement in tetralogy of Fallot. Heart. 2018;104:738-44.

9. Inage A, Kishiki K, Suzuki R, Mizuno N. Identification of optimal timing for pulmonary valve replacement in asymptomatic repaired tetralogy of Fallot using feature tracking. Circulation. 2019;140:A16016.
See Article page 196.

\section{Commentary: "If it ain't pretty, it ain't going to work pretty"}

Tain-Yen Hsia, MD

\author{
"If it ain't pretty, it ain't going to work pretty" \\ —Levi Watkins, Jr, MD \\ (June 13, 1944-April 11, 2015)
}

Levi Watkins, Jr was a trailblazer. Born in Kansas but raised in Alabama during the birth of the civil rights movement, Watkins was 11 years old when he joined his family pastor, Reverend Dr Martin Luther King, Jr, in the Montgomery bus boycott that followed Rosa Parks' arrest for refusing to give up her seat to a white passenger. Later, Watkins was the first African American to study

\footnotetext{
From the Department of Pediatric Cardiac Surgery, The Heart Center at Arnold Palmer Hospital for Children, Orlando, Fla.

Disclosures: The author reported no conflicts of interest.

The Journal policy requires editors and reviewers to disclose conflicts of interest and to decline handling or reviewing manuscripts for which they may have a conflict of interest. The editors and reviewers of this article have no conflicts of interest.

Received for publication Nov 13, 2020; revisions received Nov 13, 2020; accepted for publication Nov 16, 2020; available ahead of print Nov 23, 2020.

Address for reprints: Tain-Yen Hsia, MD, Pediatric Cardiac Surgery, Arnold Palmer Hospital for Children, 92 W. Miller St, MP307, Orlando, FL 32806 (E-mail: tain-yen.hsia@orlandohealth.com)

J Thorac Cardiovasc Surg 2021;162:207-9

0022-5223/\$36.00

Copyright (c) 2020 by The American Association for Thoracic Surgery

http://dx.doi.org/10.1016/j.jtcvs.2020.11.053
}

\section{Check for updates}

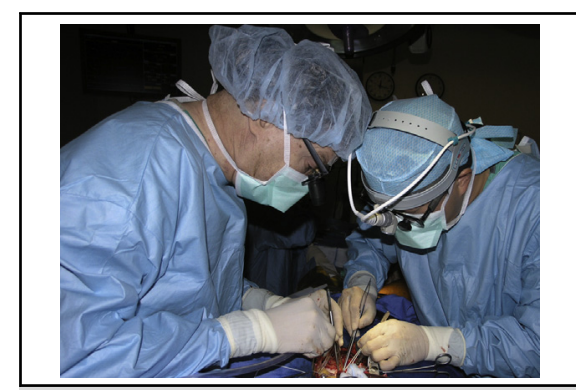

Levi Watkins, Jr reminding the author, "if it ain't pretty, it ain't going to work pretty."

\section{CENTRAL MESSAGE}

Unique shapes of the recon-

structed right ventricular outflow tract following tetralogy of Fallot repair are associated with worse late outcomes.

medicine at Vanderbilt University and was the sole African American by the time he graduated. He entered surgical training as an intern at Johns Hopkins Hospital in 1971 and survived its notoriously difficult pyramidal scheme to become its first African American Chief Resident in Cardiac Surgery. Just 7 months after completing training, as a 